Published in final edited form as:

Biochemistry. 2020 October 20; 59(41): 4039-4050. doi:10.1021/acs.biochem.0c00479.

\title{
The 15-aa repeat region of Adenomatous polyposis coli is intrinsically disordered and retains conformational flexibility upon binding $\beta$-catenin
}

\author{
Aaron J. Rudeen ${ }^{1}$, Justin T. Douglas ${ }^{2}$, Minli Xing ${ }^{2, \#, ~ W . ~ H a y e s ~ M c D o n a l d ~}{ }^{3}$, Audrey L. Lamb ${ }^{1}$, \\ Kristi L. Neufeld ${ }^{1,}{ }^{*}$ \\ ${ }^{1}$ Department of Molecular Biosciences, University of Kansas, Lawrence, KS 66045 \\ ${ }^{2}$ Nuclear Magnetic Resonance Core Laboratory, University of Kansas, Lawrence, KS 66045 \\ ${ }^{3}$ Department of Biochemistry, Vanderbilt University, Nashville, TN 37203
}

\section{Abstract}

The tumor suppressor Adenomatous polyposis coli (APC) is a large, multi-domain protein with many identified cellular functions. The best characterized role of APC is to scaffold a protein complex that negatively regulates Wnt signaling via $\beta$-catenin destruction. This destruction is mediated by $\beta$-catenin binding to centrally located 15 - and 20 -amino acid (aa) repeat regions of APC. Greater than $80 \%$ of cancers of the colon and rectum present with an $A P C$ mutation. Most carcinomas with mutant $A P C$ express a truncated APC protein which retains the $\sim 200$-aa long 15-aa repeat region. The current study demonstrates that the 15-aa repeat region of APC is intrinsically disordered. We investigated the backbone dynamics in the presence of $\beta$-catenin, and predicted residues that may contribute to transient secondary features. This study reveals that the 15-aa region of APC retains flexibility upon binding $\beta$-catenin and that APC does not have a single, observable "highest affinity" binding site for $\beta$-catenin. This flexibility potentially allows $\beta$-catenin to be more readily captured by APC and then remain accessible to other elements of the destruction complex for subsequent processing.

\section{Keywords}

APC; Intrinsically Disordered Protein; $\beta$-catenin; Cancer Biology; Stoichiometry; NMR; Structure-Function

\section{INTRODUCTION}

Acquisition of mutations that truncate the tumor-suppressor Adenomatous polyposis coli (APC) has long been established as an early, if not initiating event in the development of sporadic and familial colorectal cancer ${ }^{1,2}$. Central to the tumor-suppressive function of APC

\footnotetext{
*Please address correspondence to Kristi Neufeld, Department of Molecular Biosciences, University of Kansas, 1200 Sunnyside Ave., Lawrence, KS 66045 Tel. (785) 864-5079 klneuf@ku.edu.

\#Present address: BioNMR Core Facility, University of Michigan, Ann Arbor, MI 48109

CONFLICTS OF INTEREST

The authors declare that they have no conflicts of interest with the contents of this article.
} 
is its key role in the so-called $\beta$-catenin destruction complex ${ }^{3}$. This complex, consisting of APC, Axin, and the kinases GSK3 $\beta$ and CK1, is responsible for regulating levels of the transcription co-factor $\beta$-catenin, and is inhibited by extracellular Wnt ligands. Binding of ligand to Wnt co-receptors inhibits the destruction complex, resulting in an accumulation of cytosolic $\beta$-catenin, which translocates to the nucleus and activates genes responsible for cellular proliferation, among others ${ }^{3}$.

C-terminally truncated APC protein fragments are presumed to alter the $\beta$-catenin destruction complex architecture and function. The precise consequences of these truncations have proven difficult to resolve, in part due to the high degree of intrinsic structural disorder proposed for APC. Algorithms developed to estimate degrees of secondary structure and disorder have predicted $>70 \%$ of APC to be in an extended, disordered conformation ${ }^{4}$. Intrinsically disordered proteins (IDPs) or intrinsically disordered regions (IDRs) of proteins are gaining increasing attention for their importance in signaling cascades, scaffolding, and other molecular functions ${ }^{5,6}$.

Proteins that contain few elements of secondary structure are more extended, which has led to development of the proposed 'fly-casting' mechanism. This mechanism suggests that disorder increases the capture radius for specific interactions and speeds molecular recognition ${ }^{7}$. In the context of the $\beta$-catenin destruction complex, this 'fly-casting' ability of APC would function to rapidly sequester cytosolic $\beta$-catenin and increase its local concentration within the destruction complex. Disorder of bound proteins could also increase access to post-translational modification enzymes, and speed dissociation. ${ }^{8}$

Mutations that truncate APC most often occur in a central region aptly named the mutation cluster region ${ }^{9}$. The middle portion of APC includes a series of 15 -amino acid (aa) repeats and 20 -aa repeats (Figure 1A). The 15- and 20-aa repeat regions can each bind $\beta$-catenin directly ${ }^{10,11}$. Phosphorylation of the 20 -aa repeats, but not the 15 -aa repeats, greatly increases binding affinity in vitro ${ }^{10-12}$. Retention of the APC 15 -aa repeats in a majority of colon tumors has led to the proposed "just-right" signaling model ${ }^{13}$. In this model, APC mutations that retain some capacity to bind and regulate $\beta$-catenin provide a selective advantage over complete abolition of all binding sites ${ }^{13}$. Because the 15 -aa repeat region of APC is retained in the majority of colon cancer-associated truncated APC proteins, this region is predicted to possess functions necessary for oncogenesis and thus, is an important area to focus our attention.

Very few structural biology tools have been used to evaluate the C-terminal 2000 amino acids of APC, due primarily to the large extent of predicted intrinsic disorder. To our knowledge, the only structural information available for the 15 -aa repeat region is a crystal structure solved by Weis et al. ${ }^{11}$ of $\beta$-catenin bound with a 15 -mer peptide representing the first of four 15-aa repeats, repeat "A". Of the APC 15-aa repeats, repeats B, C, and D are separated by 4 and 2 residues, respectively, whereas repeat A is separated from repeat B by 101 residues.

For this study, we generated APC constructs to model the 15-aa repeat region (APC15R), and the tightly clustered repeats B-D (APC15R-BCD) absent repeat A and the linker 
region (Figure 1B). Table S1 converts the numbering of residues for APC15R-BCD used throughout this paper to full-length APC residue numbers for easier interpretation of the figures. Sequence similarity of the 15-aa repeats (Figure 1C and D) raises the potential that each of the four repeats has the capacity to bind $\beta$-catenin. While the contribution of the 15 -aa repeats in regulating cellular $\beta$-catenin levels ${ }^{12}$ and the binding affinities of some individual repeats ${ }^{10}$ have been investigated, the stoichiometry of $\beta$-catenin binding to the 15 -aa repeat region as a whole, and how $\beta$-catenin specifically associates with APC have not been determined.

In this study, we show that the 15-aa repeat region of APC largely lacks classical secondary structural features such as $\alpha$-helices or $\beta$-strands, though it can be induced to form a helix as measured by circular dichroism. We have completed the NMR backbone assignment of APC15R-BCD, and have analyzed the association of this fragment with $\beta$-catenin in solution. Our results demonstrate that the 15 -aa repeat region of APC associates with $\beta$ catenin to form higher order complexes in solution, that this region can bind more than one $\beta$-catenin at the same time, and that APC remains disordered upon binding. Additionally, our data suggest that there is not one single "highest affinity" APC site that $\beta$-catenin binds to, but rather, $\beta$-catenin can associate with APC in multiple different ways.

\section{MATERIALS AND METHODS}

\section{Protein Expression and Purification}

Gene sequences for the APC constructs used in this study were cloned from a previously generated plasmid containing full-length human APC. ${ }^{16}$ Cloned fragments were ligated into the pET28b (Novagen) expression vector, which contains an N-terminal 6X-His tag. Sequence-verified plasmids were transformed into BL21-CodonPlus-(DE3)-RIPL E. coli cells (NEB) for expression. Cells were grown in standard LB broth containing $50 \mu \mathrm{g} / \mathrm{mL}$ kanamycin at $37^{\circ} \mathrm{C}$ with shaking (225 rpm), and induced with $0.2 \mathrm{mM}$ isopropyl- $\beta$-Dthiogalactopyranoside (IPTG) for protein expression when an OD of 0.4-0.6 was reached. Cells were allowed to express induced protein product for $3-4$ hours at $37^{\circ} \mathrm{C}$ with shaking before harvested by centrifugation at $4,000 \mathrm{rpm}, 15 \mathrm{~min}, 4^{\circ} \mathrm{C}$. Cellular pellets were resuspended in a buffer containing $50 \mathrm{mM}$ Tris $\mathrm{pH} 8.0,50 \mathrm{mM} \mathrm{NaCl}, 50 \mathrm{mM}$ imidazole, $10 \%$ glycerol, and HALT protease cocktail (Thermo). Cells were lysed by a French pressure cell $(35,000 \mathrm{psi})$, and the insoluble cellular debris was removed by centrifugation at 16,000 $\times \mathrm{g}$ for $45 \mathrm{~min}, 4^{\circ} \mathrm{C}$. Supernatant was applied to a chelating sepharose fast-flow column (Amersham Biosciences) charged with nickel chloride and pre-equilibrated in resuspension buffer. Protein retained on the column was washed with a 3 column volumes (C.V.) salt gradient (50 mM potassium phosphate $\mathrm{pH} 8.0,500 \mathrm{mM} \mathrm{NaCl}, 50 \mathrm{mM}$ imidazole, $10 \%$ glycerol). Protein was eluted with an imidazole buffer gradient (50 mM Tris $\mathrm{pH}$ 8.0, 500 $\mathrm{mM} \mathrm{NaCl}, 500 \mathrm{mM}$ imidazole, $10 \%$ glycerol). Fractions containing recombinant protein were pooled and applied to a Superdex 200 size-exclusion column (Amersham Biosciences) pre-equilibrated with $25 \mathrm{mM}$ Tris, $\mathrm{pH} 8.0,100 \mathrm{mM} \mathrm{NaCl}$, and $10 \%$ glycerol. Fractions containing recombinant protein were pooled and concentrated with Amicon Ultra centrifugal filters (Millipore). 
The central region of $\beta$-catenin (aa. 150-665) was purified as above, with one additional step. Buffer screening revealed $\beta$-catenin was not stable over time in high-imidazole buffer, nor in the tris buffer used. Therefore, as soon as $\beta$-catenin was eluted from the nickel column, pooled protein fractions were placed in 10,000 Da SnakeSkin dialysis tubing (Thermo), and dialyzed against a citrate buffer containing $50 \mathrm{mM} \mathrm{KPi} \mathrm{pH} \mathrm{8.0,100} \mathrm{mM}$ Sodium Citrate, and $10 \%$ glycerol to remove the imidazole quickly. This citrate buffer was subsequently used for all future size-exclusion chromatography for the constructs used in this study.

\section{${ }^{15} \mathrm{~N}-$ and ${ }^{13} \mathrm{C}$-labeled Protein Expression and Purification}

For protein labeling, 4 liters of cells were grown in standard LB broth containing $50 \mu \mathrm{g} / \mathrm{mL}$ kanamycin at $37^{\circ} \mathrm{C}$ with shaking $(225 \mathrm{rpm})$ to an OD of 0.7-0.8. Cells were harvested at room temperature (RT), washed once in M9 salt solution and spun down again. All cells were resuspended in 1 liter of minimal media containing the following: $100 \mathrm{~mL} 10 \mathrm{X}$ M9 salt solution $\left(30 \mathrm{~g} / \mathrm{L} \mathrm{KH} \mathrm{KO}_{4}, 66.5 \mathrm{~g} / \mathrm{L} \mathrm{Na}_{2} \mathrm{HPO}_{4}, 5 \mathrm{~g} / \mathrm{L} \mathrm{mM} \mathrm{NaCl}\right), 2 \mathrm{~mL}$ trace element solution $\left(0.6 \mathrm{mg} / \mathrm{mL} \mathrm{CaCl}_{2}, 0.07 \mathrm{mg} / \mathrm{mL} \mathrm{ZnSO}_{4}, 0.5 \mathrm{mg} / \mathrm{mL}\right.$ EDTA, $0.115 \mathrm{mg} / \mathrm{mL} \mathrm{MnCl}_{2}$ - $4 \mathrm{H}_{2} \mathrm{O}, 0.025 \mathrm{mg} / \mathrm{mL}\left(\mathrm{NH}_{4}\right) 6 \mathrm{Mo}_{7} \mathrm{O}_{24} \bullet 4 \mathrm{H}_{2} \mathrm{O}, 0.002 \mathrm{mg} / \mathrm{mL} \mathrm{H}_{3} \mathrm{BO}_{3}, 0.08 \mathrm{mg} / \mathrm{mL} \mathrm{CoCl}_{2}$, $\left.0.6 \mathrm{mg} / \mathrm{mL} \mathrm{FeCl}_{3}, 0.03 \mathrm{mg} / \mathrm{mL} \mathrm{CuSO}_{4}\right), 4 \mathrm{mM} \mathrm{MgSO}_{4}, 0.2 \mathrm{mM} \mathrm{CaCl}_{2}, 6 \mathrm{mg} / \mathrm{mL}$ Thiamine, $10 \mathrm{~mL}$ 100X BME Vitamins (Sigma), $50 \mu \mathrm{g} / \mathrm{mL}$ kanamycin, $4 \mathrm{~g}$ D-glucose, and $1.5 \mathrm{~g}{ }^{15} \mathrm{~N}$ $\mathrm{NH}_{4} \mathrm{Cl}$ (Cambridge Isotope Laboratories). For ${ }^{13} \mathrm{C}$-labeled protein, $4 \mathrm{~g}$ uniformly labeled ${ }^{13} \mathrm{C}$-D-glucose (Cambridge Isotope Laboratories) was substituted for D-glucose. Cells were allowed to recover from spinning and washing for 1 hour, before induction with $1 \mathrm{mM}$ IPTG. Cells were incubated at $37^{\circ} \mathrm{C}$ with shaking $(225 \mathrm{rpm})$ for 7 hours. After 7 hours, cells were harvested and protein was purified as described above.

\section{Circular Dichroism and TFE Titration}

CD spectra were acquired at $25^{\circ} \mathrm{C}$ using a JASCO J-815, under continual purge of $\mathrm{N}_{2}$. Data were collected in triplicate at a scan speed of $20 \mathrm{~nm} / \mathrm{min}$, with a $1.37 \mathrm{~nm}$ slit width, a response of 4 seconds, and a pathlength of $0.1 \mathrm{~cm}$. Samples were exchanged into $100 \mu \mathrm{M}$ potassium phosphate, $\mathrm{pH} 7.0$ using a PD-10 desalting column (GE Healthcare Life Sciences). Sample concentration was determined by Bradford assay. Final protein concentration was $15 \mu \mathrm{M}$. To induce alpha-helix, 2,2,2-trifluoroethanol (TFE) (Sigma) was added to pre-mixed solutions of potassium phosphate buffer and protein to indicated final percentages. Solutions were incubated at RT for 10 minutes before spectra were acquired. The fraction of secondary structure elements were estimated using the program CDSSTR. ${ }^{17}$

\section{In vitro protein crosslinking}

Frozen protein aliquots were thawed, and concentration determined by Bradford assay. Proteins were diluted in triethanolamine, $\mathrm{pH} 8.0$ to $10 \mu \mathrm{M}$ final volume, and mixed according to indicated molar ratios. Protein solutions were cross-linked using $5 \mathrm{mM}$ dimethyl pimelimidate (DMP) (Thermo) overnight at $4^{\circ} \mathrm{C}$. Final reactions contained $0.1 \mathrm{M}$ triethanolamine, $\mathrm{pH}$ 8.0. Crosslinking reactions were quenched with Tris, $\mathrm{pH} 8.0$ for one hour, RT before boiling in SDS-PAGE buffer and resolution by gel electrophoresis. Protein bands were visualized by Coomassie stain and imaged on an Odyssey CLx imaging system (LiCor). 


\section{Size Exclusion Chromatography}

Frozen protein aliquots were thawed on ice, and concentration was checked by Bradford assay. Individual proteins were injected onto a Superdex 200 gel filtration column preequilibrated with a citrate buffer containing $50 \mathrm{mM} \mathrm{KPi} \mathrm{pH} \mathrm{8.0,} 100 \mathrm{mM}$ Sodium Citrate, and $10 \%$ glycerol. A 1:1 protein mixture at $83 \mu \mathrm{M}$ of each protein was incubated for 1 hour at $4^{\circ} \mathrm{C}$ before injection.

\section{Analytical Ultracentrifugation}

SV-AUC experiments were performed on a Proteome Lab XL-I (Beckman Coulter) analytical ultracentrifuge equipped with a scanning ultraviolet-visible optical system. Prior to SV-AUC analysis, all samples were dialyzed into $50 \mathrm{mM}$ potassium phosphate, $100 \mathrm{mM}$ sodium citrate, $5 \%$ glycerol, $\mathrm{pH} 7.0$ buffer. Concentrations of the samples were adjusted to $0.5 \mathrm{OD}$ (approximately $3.0 \mathrm{mg} / \mathrm{mL}$ for $\beta$-catenin, $1.5 \mathrm{mg} / \mathrm{mL}$ for APC15R, and $2.5 \mathrm{mg} / \mathrm{mL}$ for APC15R-BCD) at $280 \mathrm{~nm}$ to optimize the absorbance for the SV-AUC measurements. All experiments were conducted at $20^{\circ} \mathrm{C}$ after $\geq 1 \mathrm{~h}$ of equilibration and after the rotor had reached the set temperature, at a rotor speed of 40,000 RPM and with detection at $280 \mathrm{~nm}$. Samples and corresponding buffer alone were loaded into Beckman charcoal-epon two sector centerpiece $(12 \mathrm{~mm})$ with sapphire windows. The data were analyzed using Sedfit (Dr. Peter Schuck, NIH). Partial specific volumes of the samples were calculated using Sednterp (Professor Thomas Laue, University of New Hampshire and BITC) based on amino acid sequence and used in the analysis $(0.6985 \mathrm{~mL} / \mathrm{g}$ for APC-15R B-D, $0.7449 \mathrm{~mL} / \mathrm{g}$ for $\beta$-catenin, and $0.7372 \mathrm{~mL} / \mathrm{g}$ for the complex of the two). The buffer density and viscosity used in the analysis were also calculated using Sednterp based on buffer composition. For the $50 \mathrm{mM}$ potassium phosphate, $100 \mathrm{mM}$ sodium citrate, $5 \%$ glycerol, $\mathrm{pH} 7.0$ buffer, a density of $1.0373 \mathrm{~g} / \mathrm{mL}$ and viscosity of 0.012858 Poise were used. A continuous c(s) distribution model and a range of 0 to 15 svedbergs were used to integrate the data, with a resolution of 300 points per distribution and a confidence level of 0.95. Baseline, radial independent noise, and time independent noise were fit, while the meniscus and bottom positions were set manually. Distributions were imported into Origin (OriginLab) for analyzing peak area distribution before reporting.

\section{Mass Spectrometry}

In-gel tryptic digestion was performed on bands corresponding to 1:1 and the higher stoichiometry band to yield representative peptides from both bands. Resulting peptides were analyzed by high resolution data dependent LC-MS/MS. Briefly, peptides were autosampled onto a $200 \mathrm{~mm}$ by $0.1 \mathrm{~mm}$ (Jupiter 3 micron, 300A), self-packed analytical column coupled directly to an Q-exactive plus mass spectrometer (ThermoFisher) using a nanoelectrospray source and resolved using an 70 minute aqueous to organic gradient. Both the intact masses (MS) and fragmentation patterns (MS/MS) of the peptides were collected in a data dependent manner utilizing dynamic exclusion to maximize depth of coverage. Resulting peptide MS/MS spectral data were searched against an E. coli database to which the expressed proteins were added using MetaMorpheus (https://smith-chem-wisc.github.io/ MetaMorpheus/). MS1-peak areas were taken from both MetaMorpheus output and in parallel using Skyline (https://skyline.ms/project/home/software/skyline/begin.view). 
Estimates of differential stoichiometry were made by comparing the intensity ratios for each peptide between bands and comparing how those ratios differed for the two proteins. The MS analysis also provided coverage of the $\beta$-catenin protein termini, confirming that the protein remained intact.

\section{Protein NMR Spectroscopy}

All NMR data were collected at $5{ }^{\circ} \mathrm{C}$ on a Bruker AV $800 \mathrm{MHz}$ NMR spectrometer equipped with a triple resonance cryoprobe. Data were processed using the NMRPipe ${ }^{18}$ program and visualized and analyzed using NMRDraw and NMRView $\mathrm{J}^{19}$ and CCPN analysis $^{20}$ on the NMRBox platform ${ }^{21}$. Triple resonance NMR data were collected using $0.5 \mathrm{mM}{ }^{13} \mathrm{C}$ and ${ }^{15} \mathrm{~N}$ labeled APC15R-BCD in $50 \mathrm{mM}$ PBS, pH7.4 and $0.5 \%(\mathrm{v} / \mathrm{v})$ trimethylsilyl propanoic acid (TSP) for chemical shift referencing in a standard $5 \mathrm{~mm}$ NMR tube. Backbone resonance assignments were made by analyzing HNCACB, CBCACONH, and $\mathrm{HNCO}$ spectra. ${ }^{1} \mathrm{H}$ chemical shifts were referenced to the internal TSP signal, whereas ${ }^{15} \mathrm{~N}$ and ${ }^{13} \mathrm{C}$ chemical shifts were referenced indirectly using nuclei-specific gyromagnetic ratios.

${ }^{1} \mathrm{H}-{ }^{15} \mathrm{~N}$ TOCSY-HSQC spectrum was acquired using $1 \mathrm{mM}{ }^{15} \mathrm{~N}$ labeled APC15R-BCD in $100 \mathrm{mM}$ sodium citrate, $50 \mathrm{mM}$ potassium phosphate, $10 \%$ glycerol, $\mathrm{pH}$ 7.0. This buffer of higher ionic strength than physiological conditions was required for protein stability. ${ }^{1} \mathrm{H}_{-}{ }^{15} \mathrm{~N}$ HSQC titration experiments were performed using $80 \mu \mathrm{M}{ }^{15} \mathrm{~N}$-labeled APC15R-BCD and $80 \mu \mathrm{M}^{15} \mathrm{~N}$-labeled APC15R. Unlabeled $\beta$-catenin stock solution was titrated into the APC15R-BCD and APC15R samples, and ${ }^{1} \mathrm{H}_{-}{ }^{15} \mathrm{~N}$ HSQC spectra were recorded for each titration point.

The ${ }^{15} \mathrm{~N}\left\{{ }^{1} \mathrm{H}\right\}$ heteronuclear nuclear Overhauser effect (HetNOE) experiments were acquired using $200 \mu \mathrm{M}{ }^{15} \mathrm{~N}$ APC15R-BCD in the absence or presence of $40 \mu \mathrm{M} \beta$-catenin in 50 $\mathrm{mM} \mathrm{KPi} \mathrm{pH} \mathrm{7.0,} 100 \mathrm{mM}$ Sodium Citrate, and 10\% glycerol buffer with $1 \mathrm{mM}$ TCEP. The reference and NOE spectra were collected in an interleaved manner with each $2 \mathrm{D}$ was consisting of $1024 \times 128$ complex data points with 64 scans. The interscan delay is set to 11.75 and $6.75 \mathrm{~s}$ for the reference and NOE experiments, respectively. The NOE experiment used a train of $120^{\circ}$ hard pulses with $18 \mathrm{~ms}$ delays for a total saturation time set to $5 \mathrm{~s}$. The total experiment time equaled 5 days, 16 hours. The acquisition parameters match the recommendation of Renner et al. ${ }^{22}$ for accurate/precise characterization of fast dynamics on highly flexible proteins.

\section{RESULTS}

\section{The 15-aa repeat region of APC forms a complex with $\beta$-catenin in solution.}

Human APC contains four 15-aa repeats, as shown in Figure 1. Previous studies have suggested that individual repeats are each capable of binding to one $\beta$-catenin, and that repeat " $\mathrm{A}$ " has the highest affinity for $\beta$-catenin ${ }^{10-12}$. However, in vitro binding analyses have not been performed on the complete intact 15-aa repeat region. To further examine the stoichiometry, we incubated $\beta$-catenin with APC protein fragments that contained the 15 -aa repeats in different contexts. Addition of dimethyl pimelimidate (DMP), which has a (9.2 
$\AA$ A) spacer arm, allowed chemical cross-linking of proteins in close proximity. Figure 2A shows efficient crosslinking of IgG which serves as a positive control. SDS-PAGE analysis comparing the migration of test proteins to that of molecular weight standards estimates the molecular weights of APC15R-BCD, APC15R, and $\beta$-catenin constructs to be 15,30 and $48 \mathrm{kDa}$, respectively (Figure $2 \mathrm{~B}$ ). These values match the expected molecular weight for these proteins. The migration does not change in the presence of DMP crosslinker. The failure of DMP to covalently trap homo-oligomers indicates that these proteins do not selfassociate at the concentrations tested. As negative controls, Figure 2C shows that no APC protein fragment nor $\beta$-catenin cross-link with lysozyme, nor was DMP able to cross-link lysozyme to itself. Lysozyme (pI 11.35) was chosen because it is positively charged at our experimental $\mathrm{pH}$ of 8.0 , as is $\beta$-catenin (pI 8.71).

Based on previous isothermal titration calorimetry data ${ }^{10}$, we expected two $\beta$-catenin molecules to bind one APC15R-BCD. When incubated together at equal molar ratios, the primary APC15R-BCD / $\beta$-catenin protein band we observed migrated at a molecular weight that corresponded to a 1:1 interaction (Figure 2D). With $\beta$-catenin in 2-fold molar excess (1:2 ratio APC: $\beta$-catenin), a band appeared at a molecular weight that approximated binding of two $\beta$-catenins for each APC15R-BCD. The band corresponding to a 1:1 interaction diminished, but remained visible. The bands corresponding a 1:1 and a 1:2 interaction were excised, digested with trypsin, and analyzed by LC-coupled high-resolution mass spectrometry (MS) to determine whether the species was at a 1:2 or 2:2 stoichiometry, as the difference in molecular weight between the two is small ( $15 \mathrm{kDa})$. By measuring the ratio of peptide areas between these two bands, we determined that there was a greater stoichiometry of $\beta$-catenin in the upper band, consistent with a 1:2 ratio of APC15R-BCD to $\beta$-catenin (Figure S1). At 3 -fold molar excess of $\beta$-catenin, migrated bands were consistent with those at a 2-fold molar excess, also indicating a 1:2 ratio of APC15R-BCD to $\beta$-catenin. We did observe faint higher molecular-weight bands, however we were unable to estimate the molecular weight of these bands as accurately due to limitations in gel resolution.

The cross-linking experiments were repeated with APC15R, which contains the entire 15-aa repeat region. At a 1:1 molar ratio of APC15R: $\beta$-catenin, a majority of the visible protein band was consistent with a 1:1 complex. We observed a faint band which would be consistent with a complex of 1:2 or 2:2 ratio of APC15R: $\beta$-catenin. At a 2-fold molar excess of $\beta$-catenin, the dominant observed band was at a molecular weight that was consistent with a 1:2 or 2:2 ratio. Finally, at 3-fold molar excess of $\beta$-catenin, the band consistent with a molecular weight of a 1:2 or 2:2 ratio was diminished, and a band at a higher molecular weight appeared. This band may be a 1:3 molar ratio of APC15R-BCD: $\beta$-catenin, however we cannot rule out the possibility that it is comprised of some other stable stoichiometric ratio, such as 2:4. In any case, it is apparent that as the local concentration of $\beta$-catenin rises, APC facilitates formation of higher-order species.

To confirm that the observed APC $/ \beta$-catenin interactions were not an artifact of crosslinking, APC15R-BCD was incubated with $\beta$-catenin without addition of DMP, and the solution was subjected to size exclusion chromatography. Figure $2 \mathrm{E}$ shows the peaks representing the individual proteins, as well as the chromatogram of protein mixed in a 1:1 ratio. Apparent 
molecular weights were estimated based on column calibration with a standard mix of globular proteins. Because this APC15R-BCD is not likely globular, but rather in a more extended conformation, it is not surprising that the apparent molecular weights of APC and bound complexes of $\mathrm{APC} / \beta$-catenin eluted as if they were larger in molecular weight. Three peaks appeared in the elution of 1:1 molar ratio of APC15R-BCD: $\beta$-catenin. The right-most peak elutes at a volume consistent with the elution time of the unbound APC15R-BCD. The middle peak likely contains the complex in a 1:1 molar ratio. The left-most peak contains a higher order complex. Because there is a substantial peak of monomer APC15R-BCD in this sample, it seems most likely that the highest molecular weight elution represents two $\beta$-catenin molecules binding a single APC15R-BCD and thus leaving surplus unbound APC15R-BCD. We did not observe peaks at higher estimated molecular weights, indicating that the proteins were not aggregating or forming detectable higher order oligomers. Overall, the chromatograms were consistent with the cross-linking data for APC15R-BCD.

Next, we used analytical ultracentrifugation as a second method of estimating binding stoichiometry in a native state, absent chemical cross-linking. Figure $2 \mathrm{~F}$ shows representative spectra from APC15R-BCD and $\beta$-catenin alone, overlaid with spectra from mixtures at the indicated molar ratios. The 1:1 molar ratio mixture showed a shift of sedimentation coefficient consistent with the predicted molecular weight of a 1:1 interaction. Unexpectedly, for the 2:1 and 3:1 molar ratio samples, we observed only one prominent peak that lined up with the 1:1 peak but with a broad tail.

In total, our results demonstrate that the 15-aa repeat region of APC is capable of inducing formation of a complex containing multiple $\beta$-catenin molecules. However, only a 1:1 association was clearly observable under native experimental conditions, indicating that additional association events are of weaker affinity.

\section{NMR Backbone Assignment of APC15R-BCD}

For our initial structural analysis, we used NMR, an attractive method to study proteins that do not fold in a classic globular shape of sheets and helices. The HSQC spectrum of APC15R-BCD (aa 1130-1200, Figure 1D) revealed a narrow dispersion of peak signals from 8 - 9 ppm (Figure 3). The backbone resonances ${ }^{1} \mathrm{HN},{ }^{15} \mathrm{~N},{ }^{13} \mathrm{Ca},{ }^{13} \mathrm{C} \beta$, and ${ }^{13} \mathrm{CO}$ were assigned for APC15R-BCD. Figure 3 shows the $2 \mathrm{D}{ }^{1} \mathrm{H}_{-}{ }^{15} \mathrm{~N}$ HSQC spectrum of APC15R-BCD annotated with the ${ }^{1} \mathrm{HN},{ }^{15} \mathrm{~N}$ assignment of residues S12-S94. Overall, $88.7 \%$ of the non-proline backbone resonances were assigned. Residues of APC15R-BCD not assigned were M1, S3, and $\mathrm{H} 6$ through $\mathrm{S} 11$ of the hexa-histidine tag. Backbone ${ }^{1} \mathrm{H},{ }^{15} \mathrm{~N}$, and ${ }^{13} \mathrm{C}$ assignments have been deposited in the BMRB data bank under accession number 27766. In addition to the NMR characterization and backbone assignment of APC15R-BCD, we expressed and purified ${ }^{15} \mathrm{~N}$-labeled APC15R. This fragment allowed us to compare observations of a polypeptide containing all four 15-aa repeats, with APC15R-BCD, which contains only three clustered repeats (Figure 1B). Figure S2 shows overlay of the ${ }^{1} \mathrm{H}_{-}{ }^{15} \mathrm{~N}$ HSQC spectra of APC15R (red) and APC15R-BCD (blue). 71 of the backbone amide peaks (93.4\%) from the APC15R-BCD spectrum matched peaks from the APC15R spectrum and 5 of the backbone amide peaks showed small chemical shift changes, which are deemed insignificant. Nearly all of the peaks in the fingerprint spectrum of BCD fragment overlap 
with peaks in the larger APC15R construct, indicating that truncating the A-repeat and linker region does not impact the ${ }^{1} \mathrm{H}$ and ${ }^{15} \mathrm{~N}$ chemical shifts of the smaller BCD construct. We envision that the APC15R protein adopts an extended conformation that does not resemble a globular protein with standard a-helix or $\beta$-sheet secondary structure elements. Segments of this protein that are expressed and purified still maintain an in vitro conformation identical to that of the complete region.

\section{Secondary Structural Analysis of APC15R-BCD.}

Proteins mostly devoid of classical secondary structure elements such as helices and sheets can still possess preformed structural elements that play important roles in molecular recognition ${ }^{23}$. To test whether any pre-formed structural elements could be discerned by conventional secondary structural analysis, we examined APC15R-BCD using circular dichroism (CD) spectroscopy. Initial $\mathrm{CD}$ spectra acquired at $25^{\circ} \mathrm{C}$ and $\mathrm{pH} 7.0$ showed a large minimum at $200 \mathrm{~nm}$, as well as a slight shoulder minimum at $222 \mathrm{~nm}$ (Figure 4A). Using the program $\operatorname{CDSSTR}^{17}$, we estimate a $4 \%$ a-helical and $18 \% \beta$-sheet propensity. These results suggest APC15R-BCD may possesses a small fraction of transient $\alpha$-helix and/or $\beta$-sheet.

To determine if APC15R-BCD could be induced to form a helix, we performed a titration with 2,2,2-trifluoroethanol (TFE). Experimental evidence has suggested that titration with TFE is an effective method to identify regions of proteins that undergo helical transitions upon binding to a protein partner. ${ }^{26}$ Titration with TFE resulted in a coil-helix transition, as is apparent by the gradual loss of the $200 \mathrm{~nm}$ minimum with concomitant appearance of minimums at $208 \mathrm{~nm}$ and $222 \mathrm{~nm}$ by 20\% TFE addition (Figure 4B). We used CDSSTR to quantify the spectra and estimate the fraction of a-helix formed upon addition of TFE. Figure 4C, which plots the fraction of a-helix as calculated by the CDSSTR program versus percent TFE, shows an inflection point at around $\sim 30 \%$ TFE addition. This result demonstrates that APC15R-BCD is inclined to form a-helical or helix-like structure under conditions favorable to helix formation.

To further identify specific residues that may be involved in preformed structural elements, we predicted the ${ }^{15} \mathrm{~N}$ chemical shifts of APC15R-BCD using the sequence-corrected "random coil" ${ }^{15} \mathrm{~N}$ chemical shift library developed by Braun et al. ${ }^{24}$ This library was created to test the hypothesis that the greatest predictor of the ${ }^{15} \mathrm{~N}$ chemical shift of a given residue is the identity of the preceding amino acid. Braun et al. demonstrated that for denatured proteins the predicted chemical shift agrees with experimental data within \pm $2 \mathrm{ppm}$. Additional studies have shown that this strategy is effective at predicting unfolded peptides from those which are partially and fully folded. ${ }^{27}$ Figure $4 \mathrm{D}$ plots the measured ${ }^{15} \mathrm{~N}$ chemical shifts for APC15R-BCD in PBS versus the predicted ${ }^{15} \mathrm{~N}$ chemical shifts based the random coil library (black dots). Points along the diagonal agree well $\left(\mathrm{R}^{2}=\right.$ 0.87 ) between the measured and predicted values, suggesting that these residues are not part of well-structured regions. On the other hand, residues whose predicted and measured values differ by more than one z-score suggest that these portions of the APC15R-BCD are contributing to intramolecular structural elements, i.e. hydrogen bonds or salt bridges. The predicted ordered residues include V15, R65, H66, I71, Y73, Y77, I81, and S94. 
We hypothesize that these residues are important in regulating the local order present in APC15R-BCD. As a control, this method was tested on ubiquitin (a model for a well-folded protein). The measured ${ }^{15} \mathrm{~N}$ chemical shift values were taken from BMRB entry 5387. The plot of measured versus predicted ${ }^{15} \mathrm{~N}$ chemical shifts for ubiquitin (Fig. 4D, pink dots) are highly scattered, indicating a stable, compact secondary structure. The absence of correlation $\left(\mathrm{R}^{2}=0.54\right)$ for ubiquitin demonstrates the ability of this prediction method to distinguish highly-structured proteins from those with less compact structural elements.

Finally, we used the web server CSI 3.0 to identify and predict regions of secondary structure. CSI 3.0 takes input from assigned backbone NMR chemical shifts $(\mathrm{Ca}, \mathrm{CO}, \mathrm{C} \beta$, $\mathrm{N}, \mathrm{Ha}, \mathrm{NH}$ ) and uses a multi-step algorithm combining four separate programs to accurately predict 11 different types of secondary structure ${ }^{25}$. Figure 4E shows the secondary structure assignment for APC15R-BCD. CSI 3.0 calculated a short segment from residues 26-33 to be $\beta$-turn type I, with no predictions of $a$-helix or $\beta$-sheet. Therefore, it is likely any secondary structural features observable in the previous analyses are highly transient and heterogeneous in nature.

\section{Titration of APC15R-BCD with $\beta$-catenin}

With the backbone peaks of APC15R-BCD assigned, we sought to identify key features of the $\beta$-catenin/APC interaction. The $\beta$-catenin protein (aa. 150-665) was not soluble in the PBS buffer in which the backbone peaks of APC15R-BCD were assigned. Buffer screening revealed that citrate buffer was suitable for both APC and $\beta$-catenin (see methods). Because the ${ }^{1} \mathrm{H}-{ }^{15} \mathrm{~N}-\mathrm{HSQC}$ spectra of APC15R-BCD in PBS and citrate buffer did not overlap perfectly, we analyzed a new $3 \mathrm{D}^{1} \mathrm{H}_{-}{ }^{15} \mathrm{~N}$ TOCSY-HSQC spectrum of the ${ }^{15} \mathrm{~N}$-labeled APC15R-BCD in the citrate buffer. Figure S3 shows a representation of the resonance assignment validation process which confirmed to us that the resonance assignments were transferred correctly. Assignments made in PBS buffer are included in Figure S4.

Titration of APC15R-BCD (Figure 5A) with $0.5-2.0$ molar excess of $\beta$-catenin resulted in a general decrease in peak intensities. This confirms that APC15R-BCD binds to $\beta$-catenin in vitro, and that all APC residues appear impacted in response to $\beta$-catenin binding. Unexpectedly, no significant chemical shift changes were observed. Figure $5 \mathrm{C}$ shows the ratio of peak heights upon titration of a 1:1 to 1:0 APC/ $\beta$-catenin molar ratio. APC15R has a linker region that is not predicted to associate with $\beta$-catenin. We hypothesized that in a titration of APC15R with $\beta$-catenin, peaks from this linker region would not change in response to $\beta$-catenin binding. However, as was seen with APC15R-BCD, titration of APC15R with $0.5-2.0$ molar excess of $\beta$-catenin also resulted in a general decrease in all peak intensities, including those from the linker region (Figure 5B).

In order to test the specificity of the 15-aa repeat region of APC for $\beta$-catenin binding, we incubated APC15R with lysozyme at a 1:1 molar ratio. Lysozyme was again chosen because it is positively charged at our experimental $\mathrm{pH}$ (pI 11.35), like $\beta$-catenin. As expected, we observed no changes to the spectra (Figure S5) demonstrating APC15R (pI 5.61) does not interact with lysozyme. We conclude that APC15R does not merely interact with protein partners simply by electrostatic attraction. 


\section{Backbone Dynamics of APC15R-BCD}

To gain insight into the backbone dynamics of the 15-aa repeat region of APC that interacts with $\beta$-catenin, we collected heteronuclear $\left\{{ }^{1} \mathrm{H}\right\}-{ }^{15} \mathrm{~N}$ NOE relaxation rates for APC15R$\mathrm{BCD}$ in both the unbound, free state as well as upon addition of 0.2 molar-ratio $\beta$-catenin to the solution. The $\left\{{ }^{1} \mathrm{H}\right\}-{ }^{15} \mathrm{~N}$ NOE values (Figure 6) of free APC15R-BCD reinforced our conclusions that this region is highly flexible, as we do not observe continuous stretches of residues with NOE values close to 0.8 , which would indicate higher degrees of rigidity.

NOE values very low or negative are indicative of highly flexible, "random coil" like regions. Interestingly, a majority of the residues fall into a middle range between a ratio of 0.3 and 0.6. We did not observe significant changes in NOE values when a 0.2 molar ratio of $\beta$-catenin was added. Of note, residues spanning "repeat D" show a general increase in flexibility (decrease in NOE value) upon binding with $\beta$-catenin. These results indicate that the backbone dynamics of APC15R-BCD remain largely unchanged upon association with $\beta$-catenin, and that no major fold-upon-binding events are discernable.

\section{DISCUSSION}

The role of the 15-aa repeats of APC has confounded researchers for decades. Experimental evidence has suggested that the 15 -aa repeats are dispensable for the ubiquitination and down-regulation of $\beta$-catenin ${ }^{28}$. On the other hand, if $\beta$-catenin is mutated such that it cannot interact with either the 20-aa repeat region or Axin2, then the 15-aa repeats of APC appear necessary and sufficient to mediate $\beta$-catenin degradation ${ }^{29}$. It is important to note that a majority of tumors containing APC mutations lack most or all of the 20 -aa $\beta$-catenin binding repeats. Therefore, we have focused our attention on the structure and binding properties of the 15-aa repeat region alone, absent the C-terminal binding regions of APC.

\section{The 15-aa repeat region of APC lacks traditional secondary structural elements}

There are relatively few missense $A P C$ mutations in colorectal tumors. It has been proposed that the extensive intrinsic disorder present throughout the central binding repeat region of APC and high degree of binding redundancy may be a mechanism that guards against missense mutations ${ }^{30}$. Previous computational predictions suggested that the 15 -aa repeat region is intrinsically disordered. ${ }^{4}$ Our CD and NMR analyses provide evidence of only limited or transient traditional secondary structure such as helices and sheets. The chemical shift overlap of APC15R and APC15R-BCD indicates that Repeat A (and the linker region) of APC15R does not influence the folding of APC15R-BCD. Instead, we observe a striking similarity between the 15-aa repeat region and the central mutation cluster region of APC, both in ability to be induced to form helix in the presence of TFE, and in its extended nature $^{30}$. Together, our data lead us to conclude that this region of APC contains significant flexibility.

\section{$\beta$-catenin likely interacts with APC in alternative binding modes}

$\beta$-catenin binds to Repeat A of APC using the same binding groove as other binding partners E-cadherin, XTcf3, and TCF ${ }^{11}$. Indeed, the crystal structure of $\beta$-catenin with a peptide representing Repeat A showed that APC residues D1022, P1024, I1025, Y1027, and E1034 
directly contact $\beta$-catenin ${ }^{11}$. A different study reported that mutation of Y1027, S1028, and Y1031 of Repeat A (as well as the corresponding residues for repeats B-D, see Fig. 1C) was sufficient to abolish $\beta$-catenin binding to an APC fragment expressed transiently in HEK293T cells 9 . Interestingly, crystal structures solved with TCF fragments bound to $\beta$-catenin revealed at least two distinct modes of binding, with TCF utilizing variable residues to form salt bridges with specific $\beta$-catenin residues ${ }^{31}$. We hypothesize that APC can also recognize and bind $\beta$-catenin specifically, yet in alternative conformations similar to the TCF studies. Our NMR studies revealed no chemical shift changes for APC15R-BCD in solution with $\beta$-catenin titration, but rather, the simultaneous disappearance of peaks, even at sub 1:1 stoichiometric ratios. A longer peptide fragment, APC15R, produced overlapping NMR peaks with APC15R-BCD and these peaks also disappeared rather than shifted with $\beta$-catenin titration.

A potential explanation for our observation that the $\beta$-catenin-bound state of APC15R or APC15R-BCD is NMR invisible, with no shifts upon binding, is that the proteins are aggregating at higher concentrations. We do not favor this explanation because we did not observe large complexes of oligomers at the 1:1 ratio used in the SEC, AUC or cross-linking experiments. Thus, we conclude that APC15R-BCD binds in a heterogenous fashion with $\beta$-catenin that is in intermediate chemical exchange on the NMR time scale.

\section{The association of $\beta$-catenin and APC}

The high sequence similarity of the four 15 -aa repeats raises the potential that each could bind $\beta$-catenin. Our crosslinking data indicates that APC15R-BCD can facilitate formation of complexes involving more than one $\beta$-catenin when $\beta$-catenin is at a molar excess. These data support the conclusion of previous isothermal titration calorimetry data that a peptide containing repeats $\mathrm{B}, \mathrm{C}$, and $\mathrm{D}$ could bind two $\beta$-catenin molecules ${ }^{10}$.

For both APC constructs tested at a 1:1 molar ratio, a majority of the observed crosslinked protein products were at molecular weights that corresponded to a 1:1 ratio, with minor products at higher molecular weight complexes. We initially hypothesized that certain binding sites would have a higher affinity for $\beta$-catenin, and if so, then we could identify those sites. However, our NMR results did not reveal any peak shifts that would be consistent with one specific bound conformation. In total, our results do not provide evidence for a difference in affinity of a specific binding site. However, previous ITC data might indicate such a difference ${ }^{10}$.

These results are consistent with the "binding cloud" model which proposes that certain disordered regions of proteins dynamically present multiple identical, rapidly interchangeable binding sites to partners at once, existing in a "cloud" of bound conformations. ${ }^{5,32,33}$ In the context of the $\beta$-catenin destruction complex, this flexibility in binding would provide APC the ability to sequester $\beta$-catenin when appropriate, and to release it to the higher affinity, 20-aa repeat region for phosphorylation and eventual degradation.

We also observe that APC retains conformational flexibility upon binding with $\beta$-catenin. This flexibility has been described as "fuzzy", or a disorder-to-disorder association in order 
to differentiate this type of binding from traditional lock-and-key or induced fit ordered binding models. ${ }^{34,32}$ The $\beta$-catenin destruction complex is often modeled as a large globular complex with 1:1 molar ratios of all components. However, some proteins of this complex exist in extended conformations, which complicates this model and our understanding of how $\beta$-catenin is regulated. Our data as a whole support a model whereby, as $\beta$-catenin concentrations increase in the cell, APC is able to act as a molecular sponge, binding excess $\beta$-catenin in a sequential manner. This model is further supported by studies analyzing the consequence of removing the 15 -aa and/or 20aa repeat region of APC. ${ }^{35}$ The extended nature of the 15-aa repeats likely speeds molecular recognition, and allows APC to rapidly regulate free $\beta$-catenin.

It has also been proposed that the 15 -aa repeats do not simply hold onto excess $\beta$-catenin, but that they are essential to the downstream ubiquitination and degradation of $\beta$-catenin. ${ }^{36}$ In the same study, APC homologue APCL (APC2) which lacks the 15-aa repeats was observed to use the 15 -aa repeats of APC in order to down-regulate $\beta$-catenin. When the high affinity $\beta$-catenin-binding domain of E-cadherin was added to APCL, $\beta$-catenin degradation was compromised. The flexibility we observe with APC both in the bound and unbound states increases the accessibility to $\beta$-catenin, but also likely allows for fast protein exchange critical for effective $\beta$-catenin degradation.

Truncated APC that retains the 15-aa repeat region is positively selected in colon cancer cells. Therefore, some ability of APC to bind $\beta$-catenin may be required for cancer cell survival. Our finding that APC remains disordered upon $\beta$-catenin binding likely reflects another key aspect of this interaction. The 15 -aa repeats do not need to be phosphorylated to bind $\beta$-catenin, unlike the 20 -aa repeats which are lost in a majority of mutation events. ${ }^{10,37}$ This lack of phosphorylation requirement of the 15aa repeats along with the intrinsic disorder before binding and the disorder that remains after binding allows APC to retain a specific level of control over $\beta$-catenin. Therapeutics targeting this region and disrupting the specific association of $\beta$-cat to the 15 -aa repeats might be effective in causing a cancer cell to lose all remaining regulatory control of $\beta$-catenin, thus triggering cell death pathway activation.

\section{CONCLUSIONS AND SIGNIFICANCE}

This report is the first biochemical analysis of $\beta$-catenin binding to the complete 15 -aa repeat region of APC. Our findings demonstrate that the 15-aa repeat region of APC can bind more than one $\beta$-catenin molecule and that APC does not undergo structural transitions to a folded-like state upon this binding. These results can guide future studies aimed to establish the dynamics and architecture of the $\beta$-catenin destruction complex. Computational models and analysis of stoichiometry and $\beta$-catenin sequestration/turnover will also benefit from the work presented here. Finally, our peak assignment of the NMR backbone fingerprint for the 15-aa repeat region of APC will facilitate finer detailing of APC's contribution to $\beta$-catenin regulation and tumorigenesis. 


\section{Supplementary Material}

Refer to Web version on PubMed Central for supplementary material.

\section{ACKNOWLEDGMENT}

The content is solely the responsibility of the authors and does not necessarily represent the official views of the National Institutes of Health. We would like to thank Dr. Hayes McDonald for discussion and assistance with mass spec analysis, and Dr. Gonzolo de Prat Gay for technical support and discussion with the dichroism experiments.

Funding was provided by COBRE pilot project P30GM110761 (KLN, AJR), the J.R. and Inez Jay endowment (KLN), NIH R01 GM127665 (ALL) and NSF CHE-1904494 (ALL). This study was made possible by use of NMRbox: National Center for Biomolecular NMR Data Processing and Analysis, a Biomedical Technology Research Resource (BTRR), which is supported by NIH grant P41GM111135 (NIGMS). NMR backbone chemical shift assignments for APC15R-BCD have been deposited in the BMRB data bank under accession number 27766.

\section{The abbreviations used are:}

$\begin{array}{ll}\text { APC } & \text { Adenomatous polyposis coli } \\ \text { aa } & \text { amino acid } \\ \text { IDP } & \text { intrinsically disordered protein } \\ \text { RMSD } & \text { intrinsically disordered region } \\ \text { ncSPC } & \text { root-mean-square-deviation } \\ \text { CD } & \text { neighbor corrected structural propensity calculator } \\ \text { TFE } & \text { circular dichroism } \\ \text { DMP } & \text { trifluoroethanol } \\ \text { IPTG } & \text { dimethyl pimelimidate } \\ \text { C.V. } & \text { isopropyl- } \beta \text {-D-thiogalactopyranoside } \\ \text { TSP } & \text { column volume } \\ \text { NOE } & \text { trimethylsilyl propanoic acid } \\ \end{array}$

\section{REFERENCES}

(1). Kinzler KW, and Vogelstein B (1996) Lessons from Hereditary Colorectal Cancer. Cell 87, 159 170. [PubMed: 8861899]

(2). Rowan AJ, Lamlum H, Ilyas M, Wheeler J, Straub J, Papadopoulou A, Bicknell D, Bodmer WF, and Tomlinson IPM (2000) APC mutations in sporadic colorectal tumors: A mutational "hotspot" and interdependence of the "two hits." Proc. Natl. Acad. Sci 97, 3352-3357. [PubMed: 10737795]

(3). Stamos JL, and Weis WI (2013) The $\beta$-Catenin Destruction Complex. Cold Spring Harb. Perspect. Biol 5. 
(4). Minde DP, Anvarian Z, Rüdiger SG, and Maurice MM (2011) Messing up disorder: how do missense mutations in the tumor suppressor protein APC lead to cancer? Mol. Cancer 10, 101. [PubMed: 21859464]

(5). Uversky VN (2013) A decade and a half of protein intrinsic disorder: Biology still waits for physics. Protein Sci. Publ. Protein Soc 22, 693-724.

(6). Wright PE, and Dyson HJ (2015) Intrinsically Disordered Proteins in Cellular Signaling and Regulation. Nat. Rev. Mol. Cell Biol 16, 18-29. [PubMed: 25531225]

(7). Shoemaker BA, Portman JJ, and Wolynes PG (2000) Speeding molecular recognition by using the folding funnel: The fly-casting mechanism. Proc. Natl. Acad. Sci. U. S. A 97, 8868-8873. [PubMed: 10908673]

(8). Borgia A, Borgia MB, Bugge K, Kissling VM, Heidarsson PO, Fernandes CB, Sottini A, Soranno A, Buholzer KJ, Nettels D, Kragelund BB, Best RB, and Schuler B (2018) Extreme disorder in an ultrahigh-affinity protein complex. Nature 555, 61-66. [PubMed: 29466338]

(9). Kohler EM, Derungs A, Daum G, Behrens J, and Schneikert J (2008) Functional definition of the mutation cluster region of adenomatous polyposis coli in colorectal tumours. Hum. Mol. Genet 17, 1978-1987. [PubMed: 18387968]

(10). Liu J, Xing Y, Hinds TR, Zheng J, and Xu W (2006) The third 20 amino acid repeat is the tightest binding site of APC for beta-catenin. J. Mol. Biol 360, 133-144. [PubMed: 16753179]

(11). Spink KE, Fridman SG, and Weis WI (2001) Molecular mechanisms of $\beta$-catenin recognition by adenomatous polyposis coli revealed by the structure of an APC- $\beta$-catenin complex. EMBO J. 20, 6203-6212. [PubMed: 11707392]

(12). Kohler EM, Brauburger K, Behrens J, and Schneikert J (2010) Contribution of the 15 amino acid repeats of truncated APC to beta-catenin degradation and selection of APC mutations in colorectal tumours from FAP patients. Oncogene 29, 1663-1671. [PubMed: 19966865]

(13). Albuquerque C, Breukel C, van der Luijt R, Fidalgo P, Lage P, Slors FJM, Leitão CN, Fodde R, and Smits R (2002) The "just-right" signaling model: APC somatic mutations are selected based on a specific level of activation of the beta-catenin signaling cascade. Hum. Mol. Genet 11, 1549-1560. [PubMed: 12045208]

(14). Gao J, Aksoy BA, Dogrusoz U, Dresdner G, Gross B, Sumer SO, Sun Y, Jacobsen A, Sinha R, Larsson E, Cerami E, Sander C, and Schultz N (2013) Integrative analysis of complex cancer genomics and clinical profiles using the cBioPortal. Sci. Signal 6, pl1. [PubMed: 23550210]

(15). Cerami E, Gao J, Dogrusoz U, Gross BE, Sumer SO, Aksoy BA, Jacobsen A, Byrne CJ, Heuer ML, Larsson E, Antipin Y, Reva B, Goldberg AP, Sander C, and Schultz N (2012) The cBio Cancer Genomics Portal: An Open Platform for Exploring Multidimensional Cancer Genomics Data. Cancer Discov. 2, 401-404. [PubMed: 22588877]

(16). Neufeld KL, Nix DA, Bogerd H, Kang Y, Beckerle MC, Cullen BR, and White RL (2000) Adenomatous polyposis coli protein contains two nuclear export signals and shuttles between the nucleus and cytoplasm. Proc. Natl. Acad. Sci 97, 12085-12090. [PubMed: 11035805]

(17). Johnson WC (1999) Analyzing protein circular dichroism spectra for accurate secondary structures. Proteins Struct. Funct. Bioinforma 35, 307-312.

(18). Delaglio F, Grzesiek S, Vuister GW, Zhu G, Pfeifer J, and Bax A (1995) NMRPipe: a multidimensional spectral processing system based on UNIX pipes. J. Biomol. NMR 6, 277-293. [PubMed: 8520220]

(19). Johnson BA, and Blevins RA (1994) NMR View: A computer program for the visualization and analysis of NMR data. J. Biomol. NMR 4, 603-614. [PubMed: 22911360]

(20). Vranken WF, Boucher W, Stevens TJ, Fogh RH, Pajon A, Llinas M, Ulrich EL, Markley JL, Ionides J, and Laue ED (2005) The CCPN data model for NMR spectroscopy: development of a software pipeline. Proteins 59, 687-696. [PubMed: 15815974]

(21). Maciejewski MW, Schuyler AD, Gryk MR, Moraru II, Romero PR, Ulrich EL, Eghbalnia HR, Livny M, Delaglio F, and Hoch JC (2017) NMRbox: A Resource for Biomolecular NMR Computation. Biophys. J 112, 1529-1534. [PubMed: 28445744]

(22). Renner C, Schleicher M, Moroder L, and Holak TA (2002) Practical aspects of the 2D 15N-[1h]NOE experiment. J. Biomol. NMR 23, 23-33. [PubMed: 12061715] 
(23). Fuxreiter M, Simon I, Friedrich P, and Tompa P (2004) Preformed Structural Elements Feature in Partner Recognition by Intrinsically Unstructured Proteins. J. Mol. Biol 338, 1015-1026. [PubMed: 15111064]

(24). Braun D, Wider G, and Wuethrich K (1994) Sequence-Corrected 15N "Random Coil" Chemical Shifts. J. Am. Chem. Soc 116, 8466-8469.

(25). Hafsa NE, Arndt D, and Wishart DS (2015) CSI 3.0: a web server for identifying secondary and super-secondary structure in proteins using NMR chemical shifts. Nucleic Acids Res. 43, W370-W377. [PubMed: 25979265]

(26). Glover K, Mei Y, and Sinha SC (2016) Identifying Intrinsically Disordered Protein Regions Likely to Undergo Binding-Induced Helical Transitions. Biochim. Biophys. Acta 1864, 14551463. [PubMed: 27179590]

(27). Tamiola K, Acar B, and Mulder FAA (2010) Sequence-specific random coil chemical shifts of intrinsically disordered proteins. J. Am. Chem. Soc 132, 18000-18003. [PubMed: 21128621]

(28). Yang J, Zhang W, Evans PM, Chen X, He X, and Liu C (2006) Adenomatous Polyposis Coli (APC) Differentially Regulates $\beta$-Catenin Phosphorylation and Ubiquitination in Colon Cancer Cells. J. Biol. Chem 281, 17751-17757. [PubMed: 16798748]

(29). Kries J. P. von, Winbeck G, Asbrand C, Schwarz-Romond T, Sochnikova N, Dell'Oro A, Behrens $\mathrm{J}$, and Birchmeier W (2000) Hot spots in $\beta$-catenin for interactions with LEF-1, conductin and APC. Nat. Struct. Biol 7, 800. [PubMed: 10966653]

(30). Minde DP, Radli M, Forneris F, Maurice MM, and Rüdiger SGD (2013) Large Extent of Disorder in Adenomatous Polyposis Coli Offers a Strategy to Guard Wnt Signalling against Point Mutations. PLOS ONE 8, e77257. [PubMed: 24130866]

(31). Graham TA, Ferkey DM, Mao F, Kimelman D, and Xu W (2001) Tcf4 can specifically recognize beta-catenin using alternative conformations. Nat. Struct. Biol 8, 1048-1052. [PubMed: 11713475]

(32). Uversky VN (2013) Intrinsic disorder-based protein interactions and their modulators. Curr. Pharm. Des 19, 4191-4213. [PubMed: 23170892]

(33). Uversky VN (2011) Multitude of binding modes attainable by intrinsically disordered proteins: a portrait gallery of disorder-based complexes. Chem. Soc. Rev 40, 1623-1634. [PubMed: 21049125]

(34). Miskei M, Gregus A, Sharma R, Duro N, Zsolyomi F, and Fuxreiter M (2017) Fuzziness enables context dependence of protein interactions. FEBS Lett. 591, 2682-2695. [PubMed: 28762260]

(35). Roberts DM, Pronobis MI, Poulton JS, Waldmann JD, Stephenson EM, Hanna S, and Peifer M (2011) Deconstructing the Bcatenin destruction complex: mechanistic roles for the tumor suppressor APC in regulating Wnt signaling. Mol. Biol. Cell 22, 1845-1863. [PubMed: 21471006]

(36). Schneikert J, Chandra SHV, Ruppert JG, Ray S, Wenzel EM, and Behrens J (2013) Functional Comparison of Human Adenomatous Polyposis Coli (APC) and APC-Like in Targeting BetaCatenin for Degradation. PLOS ONE 8, e68072. [PubMed: 23840886]

(37). Ha N-C, Tonozuka T, Stamos JL, Choi H-J, and Weis WI (2004) Mechanism of phosphorylationdependent binding of APC to beta-catenin and its role in beta-catenin degradation. Mol. Cell 15, 511-521. [PubMed: 15327768] 
A

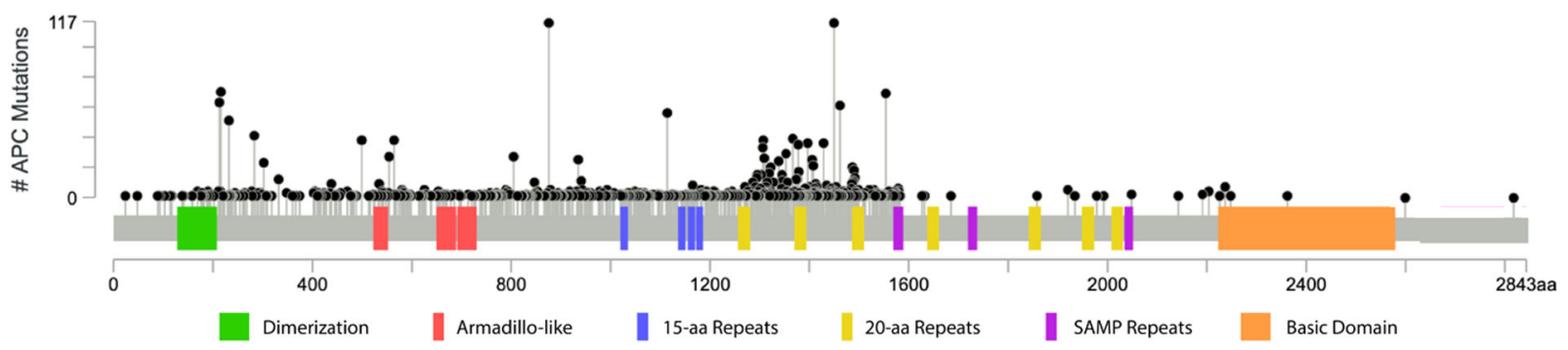

B

APC - 15R (1001-1200)

APC - BCD $\quad(1130-1200)$

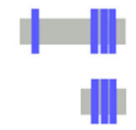

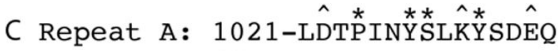
Repeat B: 1137-DDKPTNYSERYSEEE Repeat C: 1156-EERPTNYSIKYNEEK Repeat D: 1173-VDQPIDYSLKYATDI

D

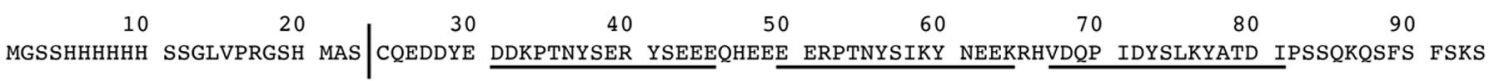

FIGURE 1. Linear representation of full-length APC protein and regions used in this study. A) Schematic of the APC protein. Black lollipops indicate location and number of truncating $A P C$ mutations in colorectal tumors of 8 compiled studies of 3,504 colorectal tumors $^{14,15}$. B) Proteins used in this study, with amino acids of APC indicated. C) Primary sequence alignment of the 15 -aa repeats. Asterisks denote conserved residues, carrots denote charge-conserved residues. D) Primary sequence of APC15R-BCD. 15-aa repeats B-D are underlined. Vertical line indicates beginning of $A P C$ sequence. Residues to the left of vertical line contain $6 \mathrm{X}-\mathrm{His}$ tag and linker sequence. 
A

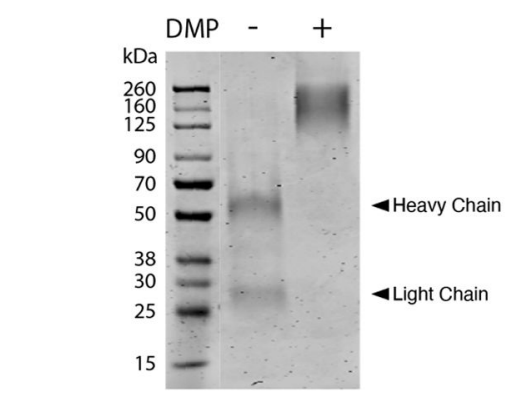

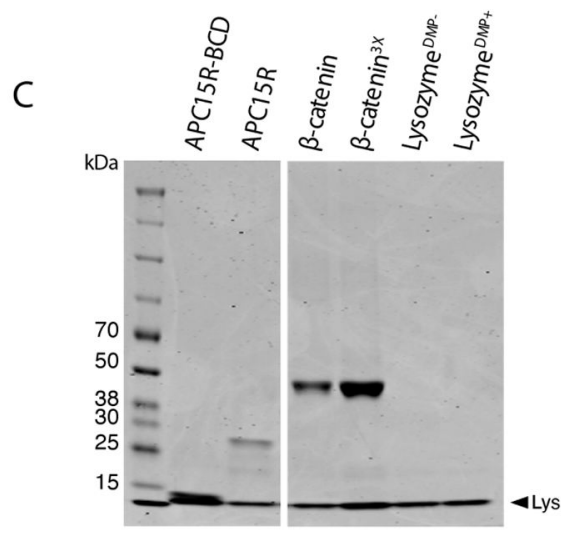

E

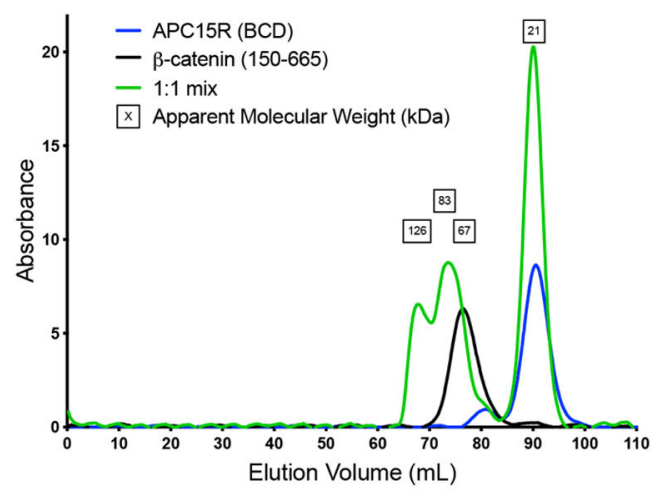

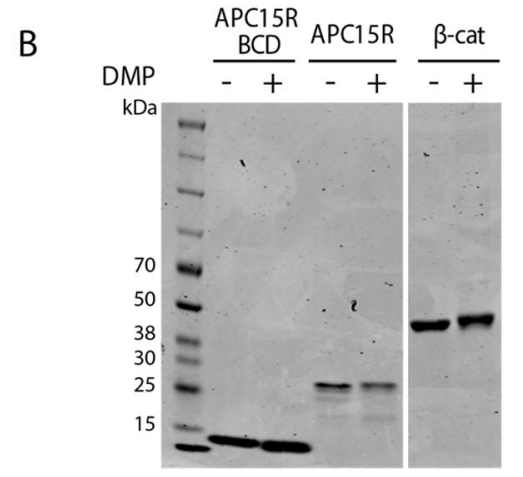

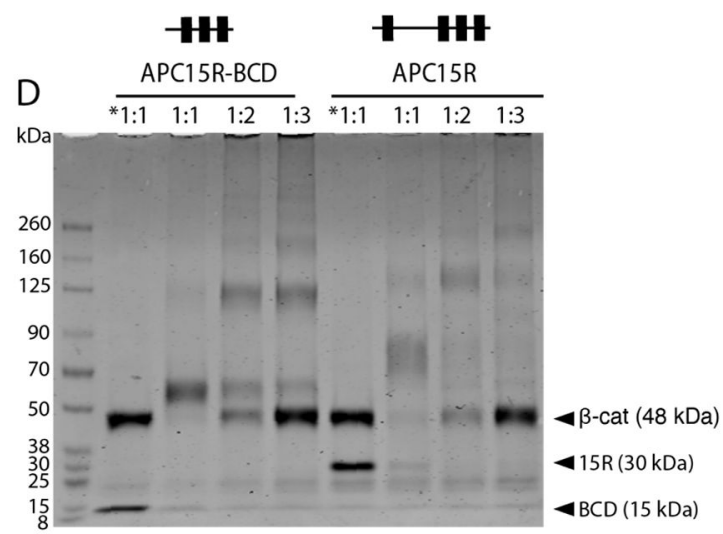

$\mathrm{F}$

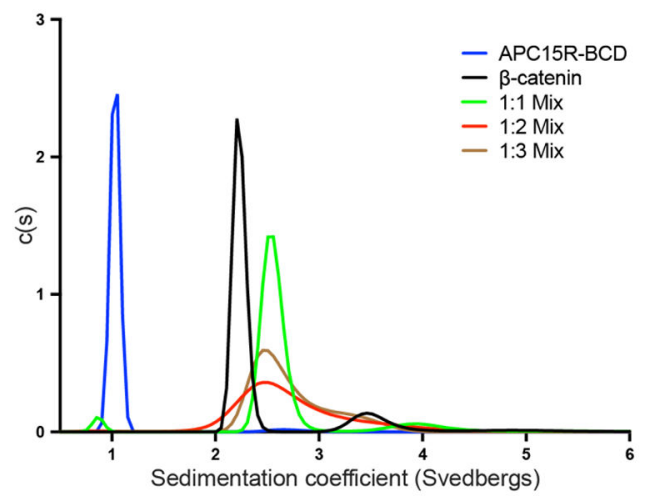

FIGURE 2. Binding of the 15-aa repeat region of APC.

A-D) Products of in vitro reactions resolved by SDS-PAGE and visualized by Coomassie stain. A) IgG incubated with and without DMP. B) Constructs tested for self-association with DMP. C) Lysozyme negative control. All samples with DMP added, except where denoted. All concentrations $10 \mu \mathrm{M}$. 3X $\beta$-catenin $=30 \mu \mathrm{M} \beta$-catenin with $10 \mu \mathrm{M}$ Lysozyme to control for 1:3 molar ratio. D) All reactions included $10 \mu \mathrm{M}$ APC protein fragment and $10 \mu \mathrm{M}$ (1:1), $20 \mu \mathrm{M}$ (1:2), or $30 \mu \mathrm{M}$ (1:3) $\beta$-catenin (150-665). Reactions without DMP indicated with *. Apparent molecular weight of unbound proteins denoted in parenthesis. E) Size exclusion chromatography spectra of APC $15 R-B C D$ and $\beta$-catenin run independently, and at a 1:1 molar ratio with no added crosslinker. Apparent molecular weights based on calibration with protein standards are indicated. F) Analytical ultracentrifugation spectra of 
APC15R-BCD alone, $\beta$-catenin alone, and indicated ratios of APC: $\beta$-catenin mixed together with no crosslinker included. 


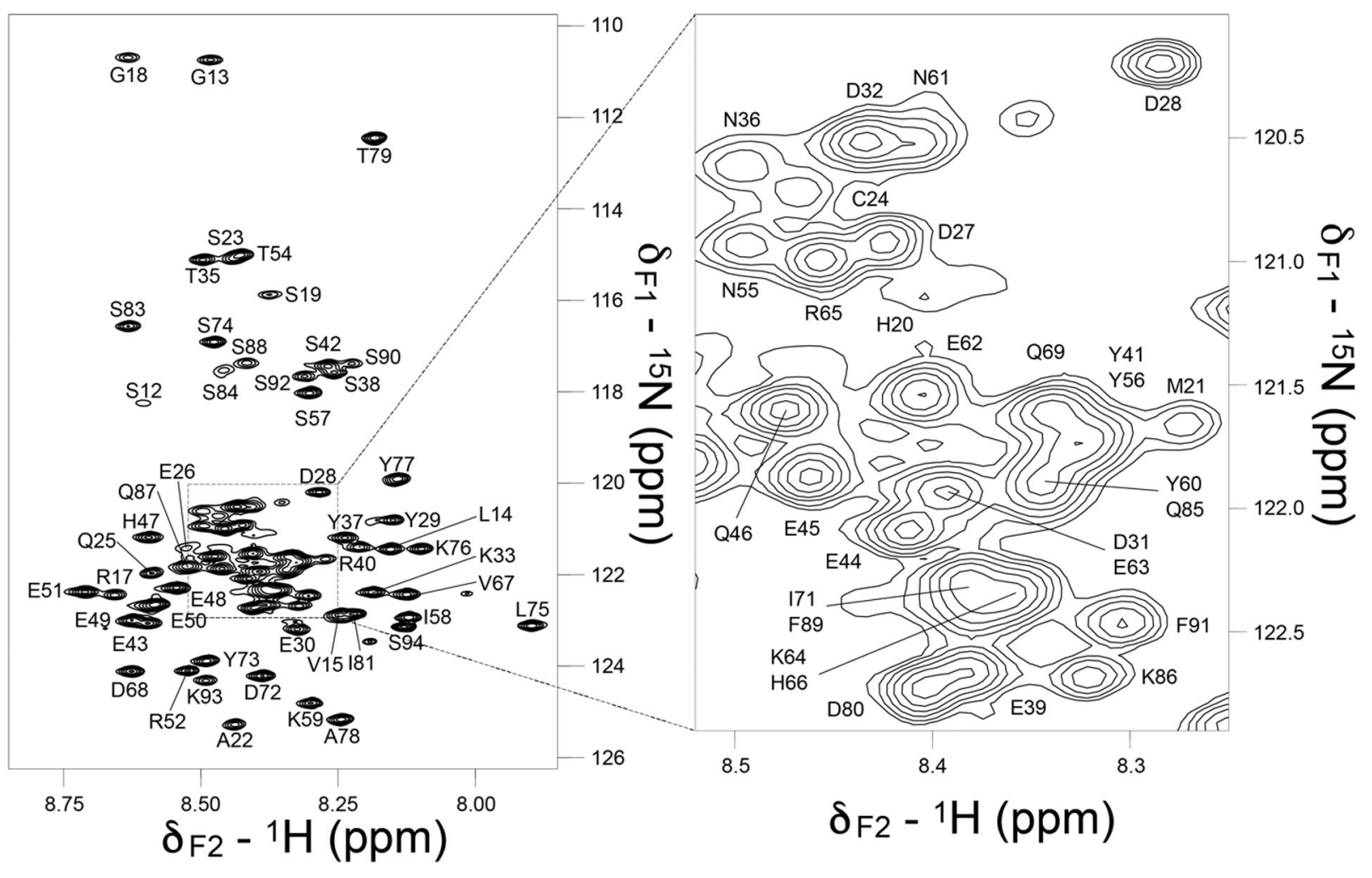

FIGURE 3. Backbone chemical shift assignment of APC15R-BCD.

${ }^{1} \mathrm{H}-15 \mathrm{~N}$ HSQC spectrum of ${ }^{15} \mathrm{~N}$ labeled APC15R-BCD in PBS buffer. The assignments of $\mathrm{S} 12-\mathrm{S} 94$ backbone $\left({ }^{1} \mathrm{HN},{ }^{15} \mathrm{~N}\right)$ are annotated. Box to right details central region with crowded peaks. 
A

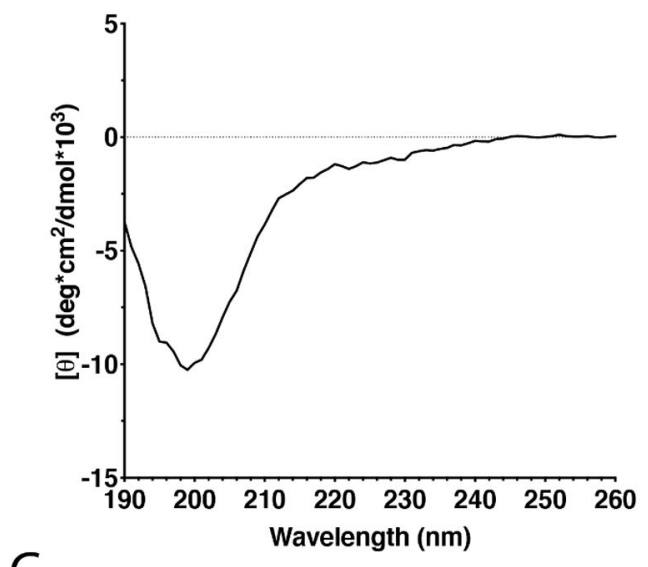

C

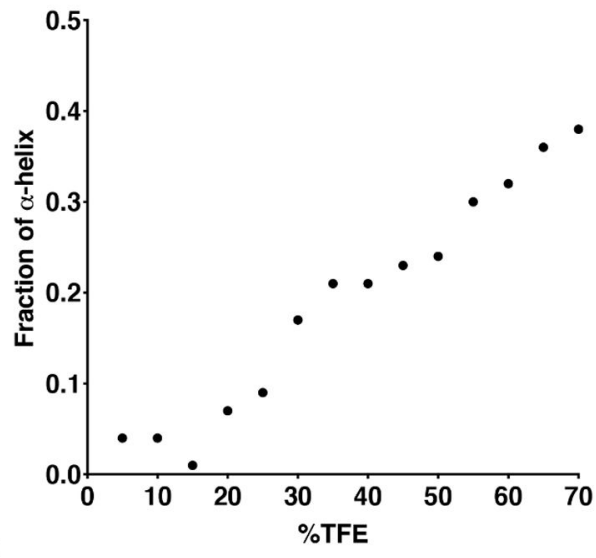

B
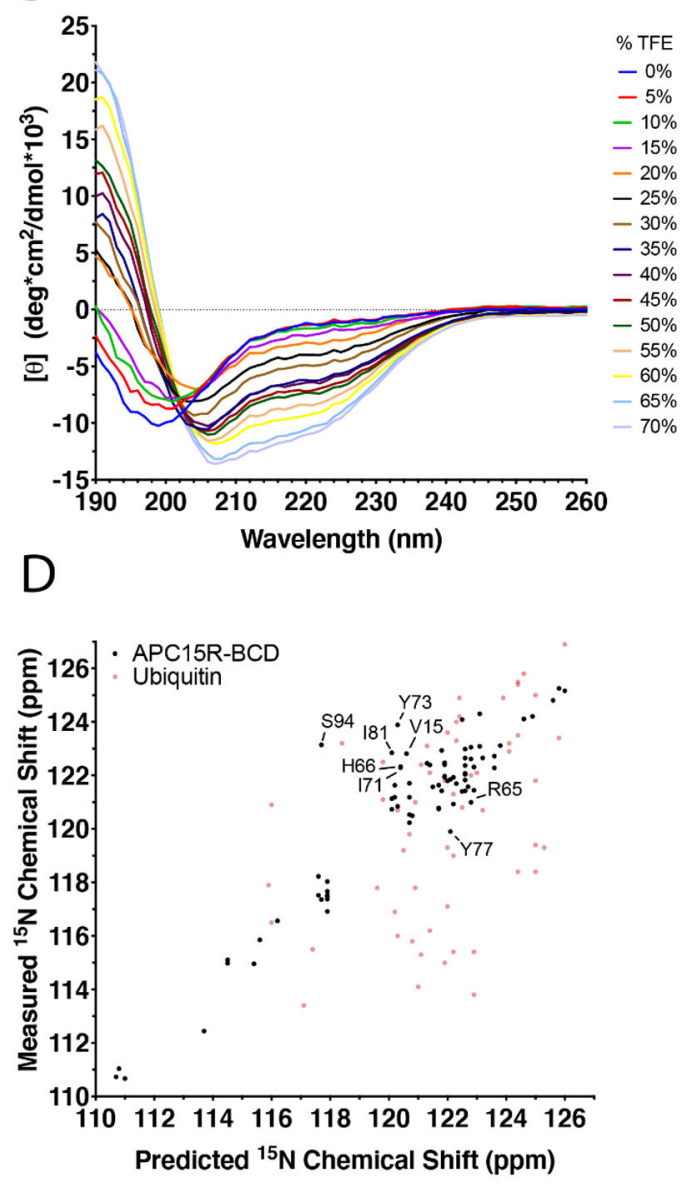

30

40

50

MGSSHHHHHHSSSGLVRGSHMASCQEDDYEDDKPTNYSERYSEEEQHEEE 50

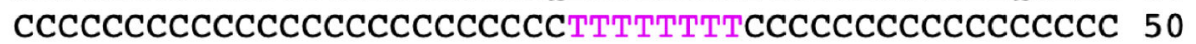

\section{1 60 70 \\ 80 $90 \quad 94$ \\ 51 ERPTNYSIKYNEEKRHVDQPIDYSLKYATDIPSSQKQSFSFSKS 94 51 CCCCCCCCCCCCCCCCCCCCCCCCCCCCCCCCCCCCCCCCCCCC 94}

FIGURE 4. Structural analysis of APC15R-BCD

A) CD Spectra of APC15R-BCD. B) TFE titration of APC15R-BCD. C) Plot of estimated a-helical content vs \% TFE for APC15R-BCD. D) Plot of measured ${ }^{15} \mathrm{~N}$ chemical shifts of APC15R-BCD vs ${ }^{15} \mathrm{~N}$ shifts predicted by a primary sequence-based algorithm developed by Braun et. al. ${ }^{24}$. Residues falling outside $1 \mathrm{z}$-score from mean regression are indicated. E) Secondary structural elements predicted for APC15R-BCD by the web server CSI 3.0 using backbone NMR chemical shifts $(\mathrm{Ca}, \mathrm{C} \beta, \mathrm{CO}, \mathrm{N}, \mathrm{Ha}, \mathrm{NH})^{25}$. Black $\mathrm{C}$ indicates coil, pink $\mathrm{T}$ indicates type I $\beta$-turn. 
A

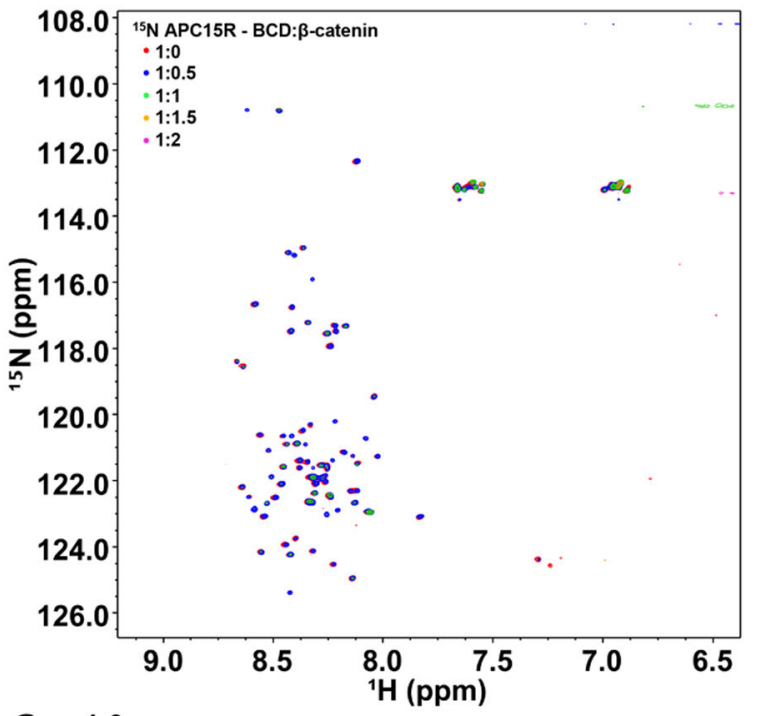

B

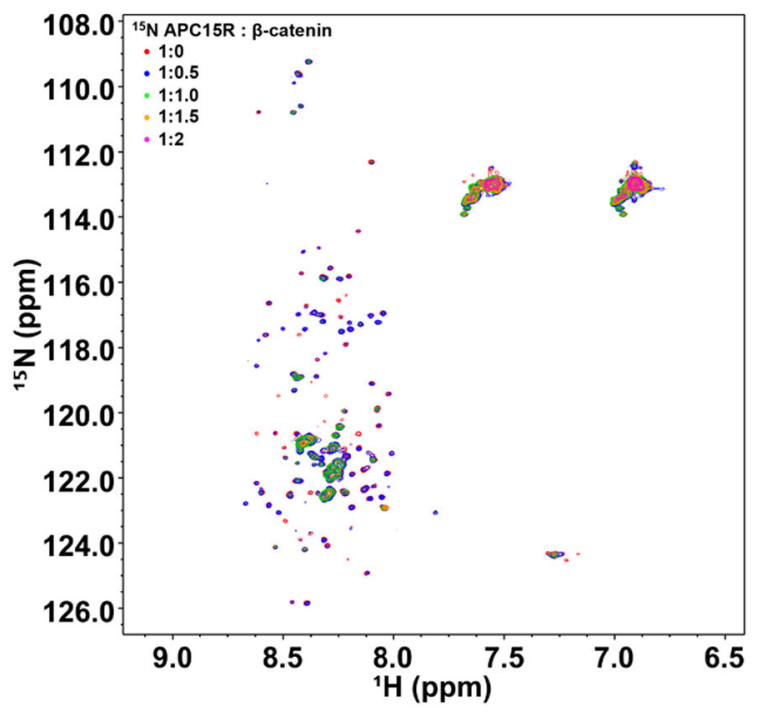

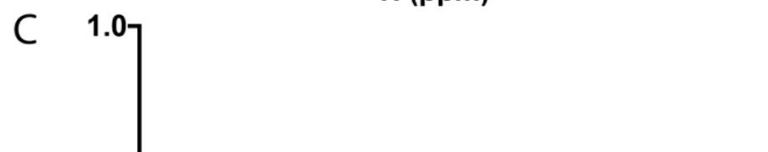

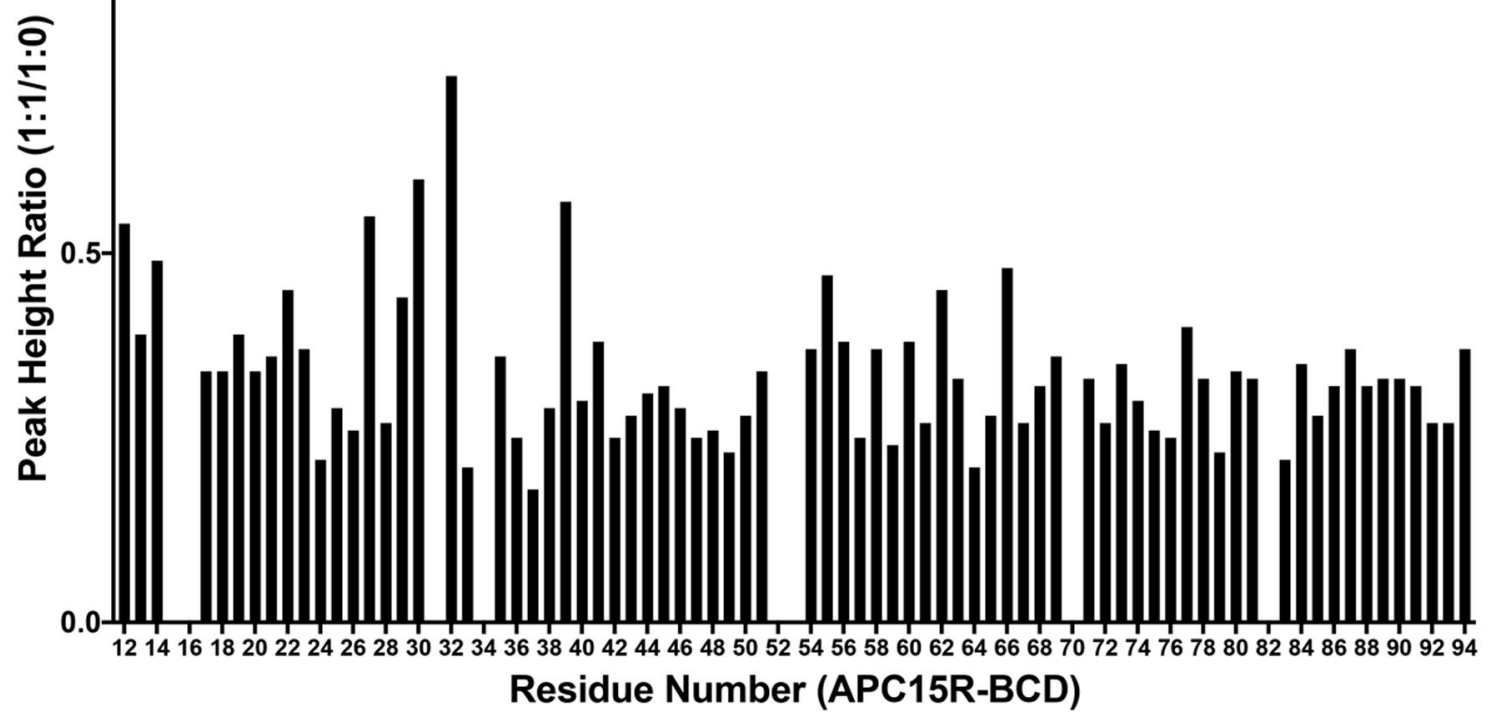

FIGURE 5. Titration of APC15R-BCD and APC15R with $\beta$-catenin.

A) Overlay of ${ }^{1} \mathrm{H}^{15} \mathrm{~N}$ HSQC spectra of ${ }^{15} \mathrm{~N}$ APC15R-BCD titrated with increasing molar ratios of $\beta$-catenin. B) Overlay of ${ }^{1} \mathrm{H}_{-}{ }^{15} \mathrm{~N}$ HSQC spectra of ${ }^{15} \mathrm{~N}$ APC15R titrated with increasing molar ratios of $\beta$-catenin. C) Peak height ratio of APC15R-BCD with 1.0 molar equivalence of $\beta$-catenin (1:1) to the peak height of free APC15R-BCD in solution (1:0). Global reduction of peak heights with no discernable chemical shift changes indicates a highly heterogenous association. 


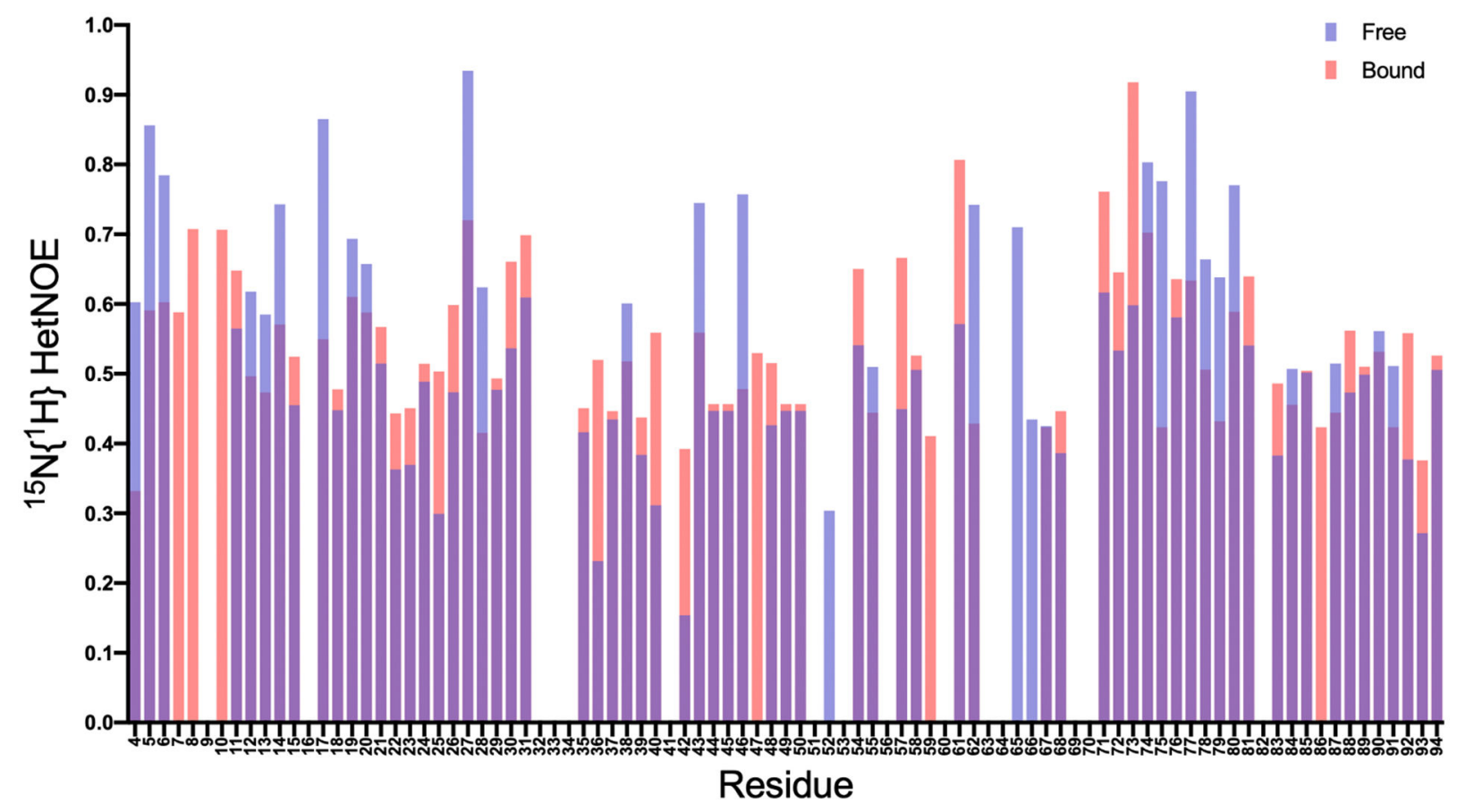

FIGURE 6. ${ }^{1} \mathrm{H}-{ }^{15} \mathrm{~N}$ Heteronuclear NOE of APC15R-BCD bound with $\beta$-catenin. Overlay of ${ }^{15} \mathrm{~N}\left\{{ }^{1} \mathrm{H}\right\}$ HetNOE spectra of APC15R-BCD (blue) with the ${ }^{15} \mathrm{~N}\left\{{ }^{1} \mathrm{H}\right\}$ HetNOE spectra after $0.2 \mathrm{M}$ equivalent of $\beta$-catenin was added to the sample tube. HetNOE values indicate general flexibility throughout the APC15R-BCD construct. A region of HetNOE values higher than mean ( 0.51 for free APC15R-BCD) from S74-S84 decreases upon interactions with $\beta$-catenin, suggesting a partial unfolding upon binding in this region. 